Brazilian Journal

of Chemical

Engineering

\title{
KINETIC MODELING AND EXPERIMENTAL VALIDATION OF A PHOTOCATALYTIC FLUIDIZED BED REACTOR FOR $n$-HEXANE DEGRADATION
}

\author{
Danielle Matsumoto $^{1 *}$, Leonardo Almeida Diniz ${ }^{1}$, Letícia Silva Castro ${ }^{1}$, \\ Antonio Carlos Silva Costa Teixeira ${ }^{1}$, Roberto Guardani ${ }^{1}$ and José Luis de Paiva ${ }^{1}$ \\ ${ }^{1}$ Universidade de São Paulo, Escola Politécnica, Departamento de Engenharia Química, São Paulo, SP, Brasil. \\ E-mail: danielle.matsumoto@gmail.com - ORCID: 0000-0003-0018-0796; ORCID: 0000-0002-9292-9102; ORCID: 0000-0001-6735-5744;
} ORCID: 0000-0002-2790-2704; ORCID: 0000-0001-5890-8546; ORCID: 0000-0001-9733-5744

(Submitted: November 23, 2018 ; Revised: April 17, 2019 ; Accepted: July 29, 2019)

\begin{abstract}
This work presents a modeling procedure for a tall photocatalytic fluidized bed photoreactor used for the photocatalytic oxidation of $n$-hexane on the anatase $\mathrm{TiO}_{2}$ surface. The modeling strategy split the reactor into two parts: a lower dense phase, with high solids concentration behaving as a bubbling bed treated as a continuous stirred tank reactor (CSTR); and an upper lean phase of low solids concentration behaving as a plug-flow reactor (PFR). The Langmuir-type kinetic parameters were obtained for the flow rate of $1.67 \times 10^{-4} \mathrm{~m}^{3} \mathrm{~s}^{-1}$ and catalyst mass of $0.1 \mathrm{~kg}$. The model revealed a good adjustment with experimental data when predicting conversion results for the same experimental conditions, but deviations grew as flow rates and catalyst loads departed from those values in which the model was obtained.
\end{abstract}

Keywords: Air treatment; Photocatalysis; VOC; Fluidized bed; N-hexane; Photoreactor.

\section{INTRODUCTION}

Currently, environmental protection agencies all over the world are strengthening laws related to atmospheric emissions of volatile organic compounds (VOC) (Assadi et al., 2014). In 1990, the Clean Air Act from USEPA raised the number of toxic compounds to be controlled from 7 to 189 . Fifty percent (50\%) of these are volatile organic compounds (VOC). Under Brazilian laws, Conselho Nacional do Meio Ambiente (CONAMA) has given VOC a definition in 2006 by Resolution 382/2006: "organic compounds at boiling point $130{ }^{\circ} \mathrm{C}$ or lower when exposed to atmospheric pressure, can contribute to the formation of photochemical oxidants". It did not stipulate emission limits, though. In 2009, the Plano Nacional de Qualidade do Ar (PNQA) brought a project to quantify local emissions of VOC in order to identify critical areas.

In that context, the development of novel technologies for the removal of VOC from air is desirable (Assadi et al., 2015). This work proposes a kinetic model determination for an innovative system capable of degrading VOC when applied in conditions where currently used technologies show lack of capability, that is, when pollutants concentrations are low or when complete combustion treatment requires high temperatures and generates toxic products from burning (Tang, 2000). The treatment process is based on the catalytic photo-oxidation of the contaminants when in contact with titanium dioxide $\left(\mathrm{TiO}_{2}\right)$ and ultraviolet (UV) radiation.

The VOC catalytic photo-oxidation process on irradiated surfaces has been studied since the 1990s (Hashimoto et al., 2006). Over the last years, application studies and method optimization reached gaseous pollutant degradation from chemical industry, for example perchlorethylene (Imoberdorg et al., 2007), trichlorethylene (Link and Kim, 2004), benzene, toluene, ethyl-benzene and xylenes (BTEX) (Park et al., 2011; Prieto et al., 2007; Yao and Kuo, 2015; Zhong

\footnotetext{
* Corresponding author: Danielle Matsumoto - E-mail: danielle.matsumoto@gmail.com
} 
et al., 2007). The technical difficulties associated with the application of this process are: low conversion caused by insufficient gas-radiation-catalyst contact (Boyjoo et al. 2017), total mineralization requirement in continuous flow (Sleiman et al., 2009) and reaction by-products formation that induce the catalyst deactivation (Rochetto and Tomaz, 2015).

Yue et al. (1983) originally proposed using the fluidized bed configuration to enhance the photoinduced synthesis of ammonia, since solids-radiation contact is increased in comparison to surfaceimmobilized reactors. Since then, Dibble and Raupp (1992), Lim and Kim (2004), Prieto et al. (2007), Park et al. (2011), Dashliborun et al. (2013), Yao and Kuo (2015), among other authors, studied the possibility of VOC photo-oxidation in fluidized bed reactors using $\mathrm{TiO}_{2}$-impregnated particles, which enhance pollutant removal efficiency in comparison to immobilized catalyst (Geng et al. 2008a). In the fluidized bed configuration, optical path, particle size distribution and bed void fraction affect solids irradiation and, hence, the reactor efficiency (Park et al., 2011).

Although a variety of works concerned with experimental data for VOC photo-oxidation in fluidized bed reactors may be found, efforts on establishing phenomenological models for these systems are scarce (Dashliborun et al., 2013). Specifically, the experimental values obtained by Prieto et al. (2007) could be well represented by coupling the continuous stirred tank reactor (CSTR) hydrodynamics with Langmuir-Hinshelwood (LH) kinetic behavior, widely used in the literature (Geng et al., 2008b). In a more detailed approach, Dashliborun et al. (2013) successfully modeled a photocatalytic fluidized reactor for methyl ethyl ketone oxidation. These authors also adopted the LH kinetic model, but its parameters were previously obtained by the differential reactor approach, and tested two non-ideal hydrodynamic models in order to predict overall conversions.

This work aims to contribute to this field by proposing a procedure for the modeling of a fluidized bed photoreactor. When fluidization occurs with gas velocities not much higher than that of solids minimum fluidization, two different regions are formed: a dense phase in the lower part of the reactor, characterized by intense bubbling and high solids hold-up; and a lean phase in the upper part, characterized by low solids hold-up and solids sticking on the reactor walls (Kunii and Levenspiel, 1991). Particularly, no published work in this field has separated the effects of lean and dense phase when considering the photoreactor hydrodynamics. This consideration has been recurrently ignored in the literature by the use of a lumped reactor volume, and might be especially important when dealing with tall reactors.

In the approach presented here, the LH kinetic parameters were first determined, and then coupled to different hydrodynamic models associated to each of the reaction regions. The two regions were thus considered as a 2-reactor series in order to predict the overall conversion. The target pollutant chosen for this study was $n$-hexane, a solvent often employed in the chemical and food industry. Mixtures with $n$-hexane are used for extraction of fat and oil in food processing and as cleaning agent in the textile and printing industries. It is also applied as a solvent for glues, as an ink remover and degreaser. However, $n$-hexane causes harmful effects on human health, so it is desirable to explore its degradation through novel technologies (USEPA, 2005).

\section{MATERIALS AND METHODS}

\section{Materials}

$\mathrm{TiO}_{2}$ powder, Anatase (purity $>99 \%$, SigmaAldrich), $<44-\mu \mathrm{m}$ particle size, was used as photoactive material in the experiments. $N$-hexane (analytical grade, purity $>99 \%$, Synth) was used as a model pollutant for oxidation, given that preliminary experiments revealed that the oxidation of this pollutant would not poison the photocatalyst.

\section{Catalyst characterization}

X-ray diffraction (XRD) in a X'Pert, Philips-1997 diffractometer in the $5-80^{\circ}(2 \theta)$ interval $(\mathrm{Cu}-\mathrm{K} \alpha$ radiation $\lambda=1.542 \AA, 2.2 \mathrm{~kW}$ ) was used to determine $\mathrm{TiO}_{2}$ powder crystalline structure. The particle size distribution was revealed by dynamic light scattering (DLS) in a Malvern $2000(0.02-2000 \mu \mathrm{m})$ and catalyst images were taken by microscopy with an Olympus BX60. Also, the specific surface area and particle morphology were determined by nitrogen adsorption treated with the Brunauer-Emmett-Teller (BET) and Barrett-Joyner-Halenda (BJH) analyses.

\section{Experimental setup}

The photoreactor used in the study was an 860$\mathrm{mm}$ length borosilicate glass tube of $50 \mathrm{~mm}$ I.D. into which a quartz tube of 30-mm O.D. was inserted. A monochromatic $254 \mathrm{~nm}$ UV-C lamp (TUV36 4P T5 $\mathrm{HO}$, Philips) was placed inside the quartz tube as the radiation source. Details of the unit for the generation of a contaminated airstream may be found in Diniz et al. (2019). All runs were carried out maintaining the inlet airstream temperature and humidity constant at $25 \pm 3{ }^{\circ} \mathrm{C}$ and $55 \pm 5 \%$, respectively. A GC-PID/ TID gas chromatograph (Meta), equipped with a photoionization detector and coupled with a MSU8V4S-RS48 automatic sampler (Meta), was used to quantify $n$-hexane in air. Both the inlet and the outlet of the reactor were connected by Teflon ${ }^{\circledR}$ tubings to a peristaltic pump (AWM-5900-AX-D, Provitec), which continuously directed ca. $100 \mathrm{~mL} \mathrm{~min}^{-1}$ to the GC loop. 
As soon as a steady-state regime was observed from the analysis of consecutive outlet samples, three inlet and three outlet concentrations were measured in order to take an averaged steady-state conversion.

Two different types of photoreactor setups were used for the photocatalytic experiments presented in this article. In Setup 1, the upper 720-mm part of the UV lamp was covered with aluminum foil, leaving $140 \mathrm{~mm}$ of irradiated height, as detailed in Figure 1A. Thus, $0.1 \mathrm{~kg}$ of $\mathrm{TiO}_{2}$ powder was put inside the annulus of the reactor, occupying just the irradiated volume, which allowed the kinetic evaluation of only the dense phase of the fluidized bed. Conversely, in Setup 2, the reactor was operated with its UV lamp fully uncovered, as shown in Figure 1B, but with the same catalyst mass (and hence dense phase volume) as that used in Setup 1 in order to evaluate the kinetics of complete reactor environment. The runs were all carried out in isothermal conditions.

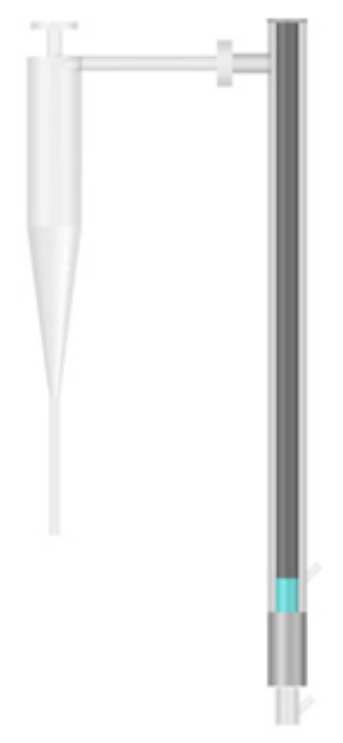

A
Figure 1. A Photoreactor Setup 1; B photoreactor Setup 2.

\section{KINETIC MODELING}

The $n$-hexane conversion (X) was defined as in Equation 1 , in which $[C]_{\text {inlet }}$ and $[C]_{\text {outlet }}$ represent, respectively, the steady-state inlet and outlet concentrations. For the kinetic model parameterization, flow rate $(Q),[C]_{\text {inlet }}$ and catalyst mass $(m)$ remained fixed during the assays. A preliminary analysis of reaction rate vs. flow rate was carried out in order to confirm that the reaction kinetics were not masstransfer limited. Afterwards, a Langmuir-type kinetics, Equation 2, was considered for the dense and lean phases, but the adsorption kinetic constant $k_{2}$ was fixed as the same value for both phases, while the reaction kinetic constants $k_{l, \text { dense }}$ and $k_{l, \text { lean }}$ had their values adjusted. The dense phase of the photoreactor was modeled as a continuous stirred-tank reactor (CSTR), given its shorter height and notable retro mixture, while the lean phase was modelled as plug-flow reactor (PFR), characterized by its homogeneous profile along a longer reactor length. Thus, the mass balance was solved, resulting in Equations 3 and 4 for the dense and lean phase, respectively, in which $V$ represents the phase volume.

$$
\begin{aligned}
& \mathrm{X}=\frac{[\mathrm{C}]_{\text {inlet }}-[\mathrm{C}]_{\text {outlet }}}{[\mathrm{C}]_{\text {inlet }}} \times 100 \% \\
& \mathrm{R}_{\text {phase }}([\mathrm{C})]=-\frac{\mathrm{k}_{1, \text { phase }}[\mathrm{C}]}{1+\mathrm{k}_{2}[\mathrm{C}]} \\
& {[\mathrm{C}]_{\text {inlet }}-\left(\frac{1+\mathrm{k}_{1, \text { dense }} \mathrm{V}_{\text {dense }} / \mathrm{Q}+\mathrm{k}_{2}[\mathrm{C}]_{\text {outlet }}}{1+\mathrm{k}_{2}[\mathrm{C}]_{\text {outlet }}}\right)[\mathrm{C}]_{\text {outlet }}=0} \\
& \frac{1}{\mathrm{k}_{1, \text { lean }}} \ln \left(\frac{[\mathrm{C}]_{\text {inlet }}}{[\mathrm{C}]_{\text {outlet }}}\right)-\frac{\mathrm{k}_{2}}{\mathrm{k}_{1, \text { lean }}}\left([\mathrm{C}]_{\text {inlet }}-[\mathrm{C}]_{\text {outlet }}\right)-\frac{\mathrm{V}_{\text {lean }}}{\mathrm{Q}}=0
\end{aligned}
$$

The complete model consisted of both phases assembled in series, such that the inlet concentration of the lean phase was set equal to the outlet concentration from the dense phase. Setup 1 was used to obtain degradation data solely for the dense phase, while Setup 2 for data from the complete reactor environment. From these data, a solver routine was used in Microsoft Excel in order to minimize the mean squared error (MSE, Equation 5) of the outlet concentrations for all the experiments (Setup $1+$ Setup 2 ) by changing the values of $k_{1, \text { dense }}, k_{l, \text { lean }}$ and $k_{2}$. Finally, a new batch of experiments was carried out with Setup 2 in order to validate the model. These validation runs tested not only the model predictions for the same operation conditions, but also different values of catalyst mass and flow rate.

$$
\operatorname{MSE}=\frac{\left[\Sigma\left([\mathrm{C}]_{\text {outlet, experimental }}-[\mathrm{C}]_{\text {outlet, model }}\right)^{2}\right]^{\frac{1}{2}}}{\text { number of experiments }}
$$

\section{RESULTS AND DISCUSSION}

\section{TiO characterization}

The X-ray diffraction pattern for the $\mathrm{TiO}_{2}$ powder is presented in Figure 2. It can be noted that the solids were pure photoactive anatase phase $\mathrm{TiO}_{2}$, as shown 


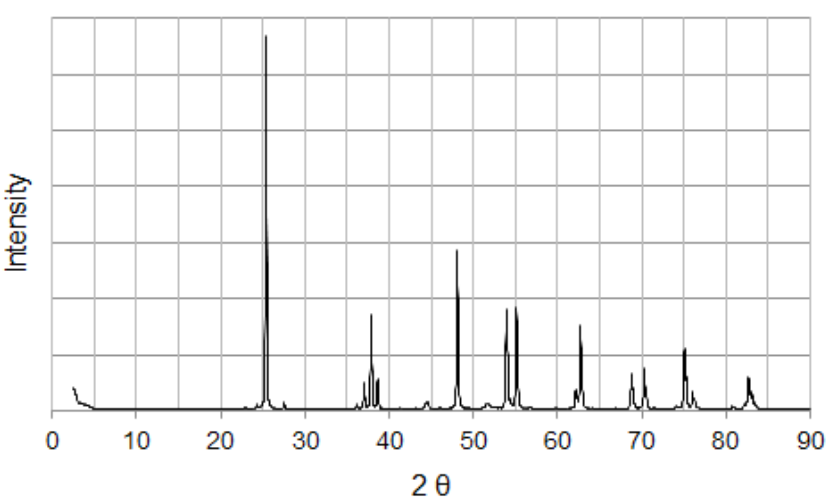

Figure 2. DRX diffraction pattern of $\mathrm{TiO}_{2}$ anatase.

by strong diffraction peaks located in $25.3^{\circ}, 37.8^{\circ}$ and $47.9^{\circ}$. Figure 3 shows the $\mathrm{TiO}_{2}$ size distribution in terms of volume fraction, as obtained by DLS analysis, revealing that the particles are mostly smaller than $3 \mu \mathrm{m}$ in size. The nitrogen adsorption isotherm is shown in Figure 4, and revealed to be a Type III isotherm characteristic of non-porous materials, with BET-BJH analyses showing specific surface area, pore diameter and pore volume of 8.13

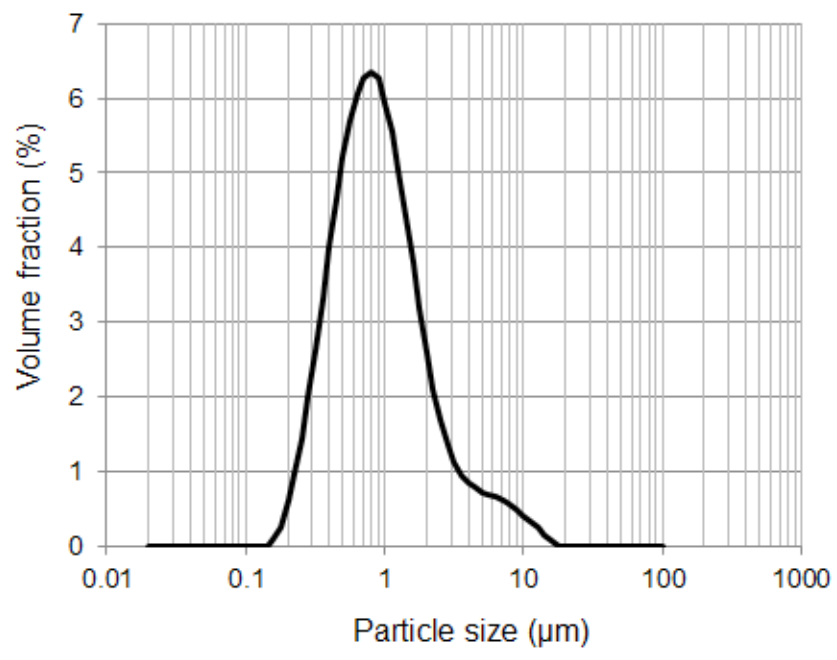

Figure 3. DLS analysis of $\mathrm{TiO}_{2}$ anatase.

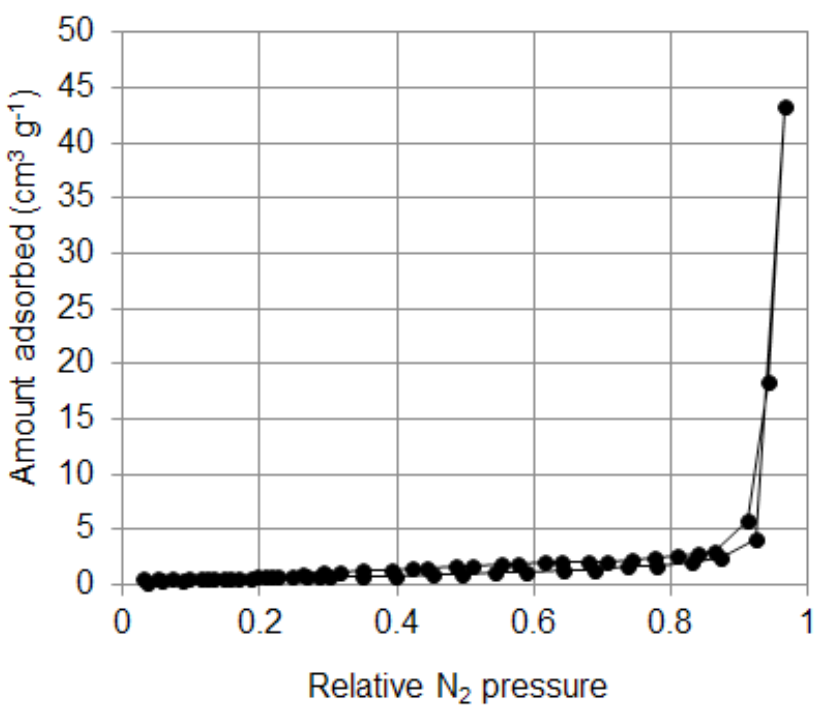

Figure 4. Adsorption isotherm for anatase $\mathrm{TiO}_{2}$ particles.

$\mathrm{m}^{2} \mathrm{~g}^{-1}, 29 \mathrm{~nm}$ and $0.23 \mathrm{~cm}^{3} \mathrm{~g}^{-1}$ for the intraparticle agglomerates. This fine size makes $\mathrm{TiO}_{2}$ a Geldart C group solid (Kunii and Levenspiel, 1991), and hence inadequate for fluidization. However, once placed inside the photoreactor and submitted to enough drag force, given some time required for pressure stabilization, the solids reorganize as millimetric spherical $\mathrm{TiO}_{2}$ agglomerates due to cohesive interparticle forces, as suggested by the photographs in Figure 5, which compare the solids before and after operation at an air flow rate of 10 $\mathrm{L} \min ^{-1}$.

After the bed pressure stabilized and agglomerates were formed, the minimum fluidization velocity $\left(u_{m f}\right)$ could be determined from the pressure drop of $0.1 \mathrm{~kg}$ of photocatalyst $v s$ flow rate diagram, shown in Figure 6 . The bed pressure drop reached a maximum value when the flow rate was set to $5.0 \mathrm{~L} \mathrm{~min}^{-1}$, which implies a minimum fluidization velocity of ca. $6.6 \mathrm{~cm} \mathrm{~s}^{-1}$.

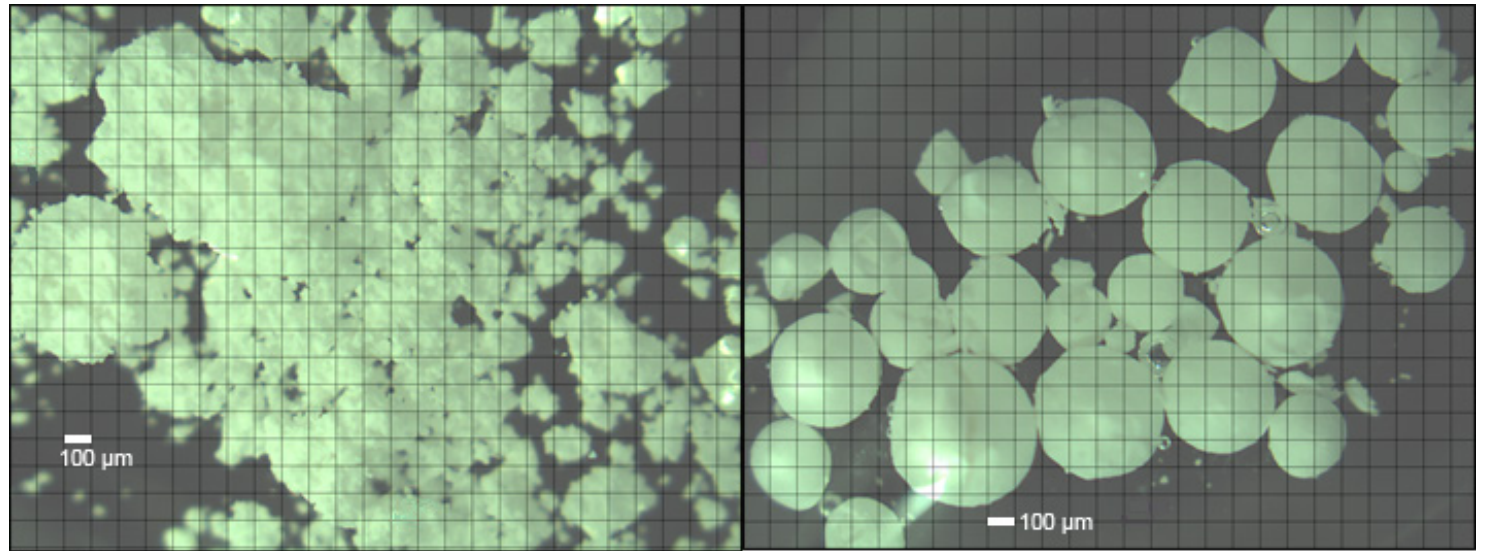

A

Figure 5. Photographs of $\mathrm{TiO}_{2}$ particles, (A) before fluidization; (B) after fluidization. 


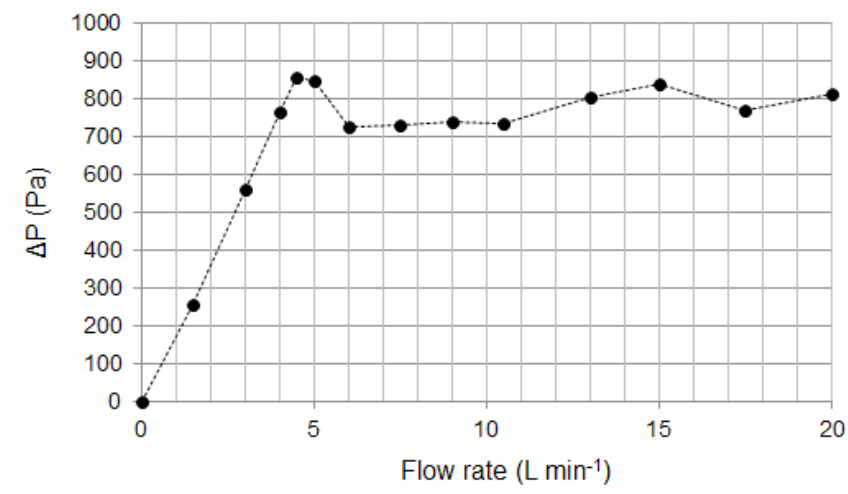

Figure 6. Pressure drop versus flow rate in the reactor.

\section{Kinetic parameter determination}

Prior to determining the mathematical relation for the model, it had to be evaluated whether the operation range to be studied was kinetically limited or mass transfer limited. Flow rate varied from 5.0 to $15.0 \mathrm{~L}$ $\mathrm{min}^{-1}$ (corresponding to residence times from 12.1 $4.0 \mathrm{~s}$ ). For that matter, the approach was based on that adopted by Kuo et al. (2011) for a multi-stage fluidized bed photo reactor. According to these authors, if the surface reaction is so rapid that the reaction rate is controlled by the transfer of pollutant from the bulk air to the catalyst surface, then the $n$-hexane degradation rate, $-r_{A}$, in $\mu \mathrm{mol} \mathrm{s}^{-1}$, must be given by Equation 6 , in which $D_{A B}$ is the diffusion coefficient of the pollutant in air, $d$ is the reactor effective diameter, $U$ is the gas velocity over a single sphere and $v$ the kinematic viscosity of air. Those authors assumed that, whatever the value of $U$, it must be linearly proportional to the superficial gas velocity of air through the photoreactor, $u$. Thus, if the flow rate increases for a constant inlet concentration, and the reaction is mass transfer limited, $-r_{A}$ should behave as in Equation 7.

$-\mathrm{r}_{\mathrm{A}}=\frac{\mathrm{D}_{\mathrm{AB}}}{\mathrm{d}} 0.6\left(\frac{\mathrm{d} \mathrm{U}}{v}\right)^{1 / 2}\left(\frac{v}{\mathrm{D}_{\mathrm{AB}}}\right)^{1 / 3}[\mathrm{C}]$

$-r_{A} \propto u^{1 / 2}$

Here, $n$-hexane degradation assays were carried out in Setup 1 with an inlet concentration of $1200 \mu \mathrm{mol} \mathrm{m} \mathrm{m}^{-3}$, which belongs to the interval of concentrations studied along this work, and flow rates of 5.0, 7.5, 10 and $15 \mathrm{~L} \mathrm{~min}^{-1}$. Setup I was used so that conversions were lower and hence concentration profiles within the reactor were less significant. The observed profile is given in Figure 7. This behaviour does not agree with that of Equation 7, and reveals that throughout the interval of flow rates considered, i.e. 5.0 - $15 \mathrm{~L} \mathrm{~min}^{-1}$, mass transfer was not the limiting step of the $n$-hexane degradation; and this interval should therefore be modelled by surface reaction kinetics.

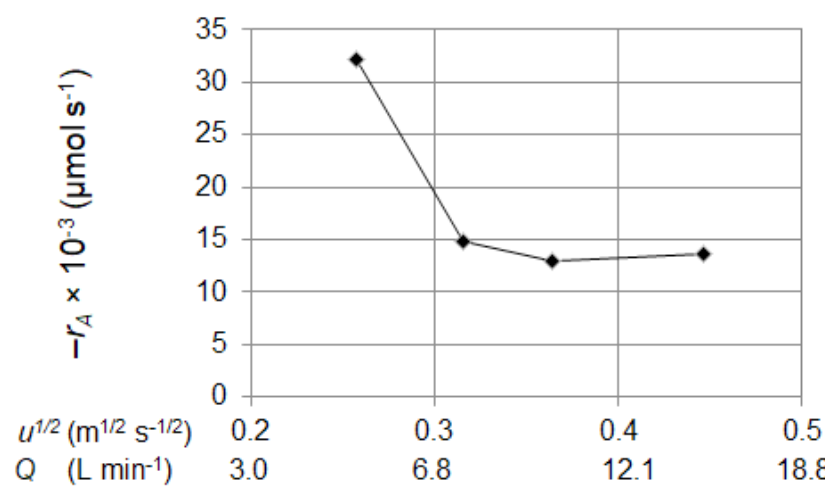

Figure 7. $-r_{A}$ vs $u^{1 / 2}$ diagram for $\mathrm{n}$-hexane. [C] inlet $=$ $1200 \mu \mathrm{mol} \mathrm{m}{ }^{-3}$.

The experimental conditions for determination of the parameters of surface reaction kinetics in the photoreactor are shown in Table 1. The phase volumes, $V_{\text {dense }}$ and $V_{\text {lean }}$, were obtained as the product of the annular cross section of the reactor and the measured height of the catalyst bed. The same experimental conditions were applied to obtain the dense and lean phase kinetic parameters in the fluidized bed.

As described above, Setup 1 was used to evaluate the performance solely of the dense phase of the fluidized reactor. Figures $8 \mathrm{~A}$ and $8 \mathrm{~B}$ show the steadystate conversion data from 43 experimental assays obtained with Setup 1 and 40 experimental points from Setup 2, respectively, both as a function of $n$-hexane inlet concentration $[C]_{\text {inlet }}$. As would be expected, conversions decrease as $[C]_{\text {inlet }}$ increase, which is justified by the effect of photocatalyst site saturation (Prieto et al., 2007). The dense phase was solely capable of degrading $16-4 \%$ of a $n$-hexane inlet stream in the range of $100-3000 \mu \mathrm{mol} \mathrm{m}^{-3}$, while the complete reactor environment degraded $40-13 \%$ in the same $[C]_{\text {inlet }}$ range. However, as can be noted from Table 1, the dense phase occupied less than one-fifth of the total reactor volume, so it seemed to be kinetically faster than the lean phase.

These 83 experimental points were treated as a training-set for the reactor performance, and the 3-parameter regression explained previously was carried out. The data from Figure 8A was modeled based on Equation 3, while the data from Figure 8B based on two reactors in series, the first one described by Equation 3 and the second by Equation 4. The MSE

Table 1. Experimental conditions used for kinetic parametrization.

\begin{tabular}{lcc}
\hline $\begin{array}{c}\text { Operational } \\
\text { parameter }\end{array}$ & Unit & $\begin{array}{c}\text { Numerical } \\
\text { value }\end{array}$ \\
\hline Catalyst mass, $m$ & $\mathrm{~kg}$ & 0.1 \\
Gas flow rate, $Q$ & $\mathrm{~m}^{3} \mathrm{~s}^{-1}$ & $1.67 \times 10^{-4}$ \\
N-hexane inlet concentration & $\mu \mathrm{mol} \mathrm{m}^{-3}$ & $100-4200$ \\
Photon flow & $\begin{array}{c}\text { Einstein s} \\
\text { Den }\end{array}$ & $1.05 \times 10^{-4}$ \\
Dense phase volume, $V_{\text {dense }}$ & $\mathrm{m}^{3}$ & $1.76 \times 10^{-4}$ \\
Lean phase volume, $V_{\text {lean }}$ & $\mathrm{m}^{3}$ & $8.29 \times 10^{-4}$ \\
\hline
\end{tabular}




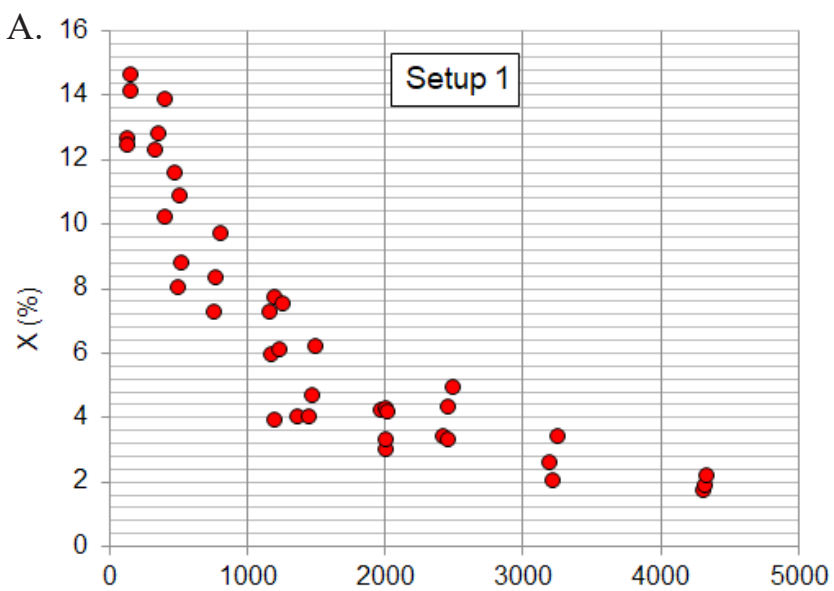

[C] inlet $\left(\mu \mathrm{mol} \mathrm{m}{ }^{-3}\right)$

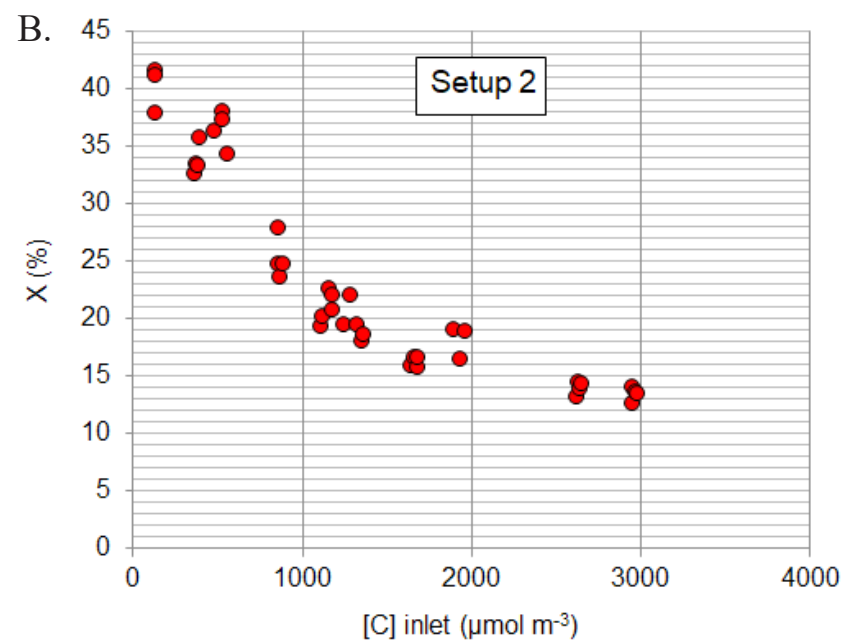

Figure 8. N-hexane conversion in the fluidized bed photo reactor, with experimental conditions as specified in Table 1. A - Setup 1; B - Setup 2.

from the complete set of experiments was minimized according to Equation 5. The optimized values for $k_{1, \text { dense }}, k_{1, \text { lean }}$ and $k_{2}$ are shown in Table 2, in which a correlation coefficient (CC, Equation 8) of 0.89 was obtained from Equation 8 (Dashliborun et al., 2013). The comparison between experimental and calculated conversion values is shown in Figures 9A and 9B for the dense phase and for the complete reactor, respectively. It can be noted that the model slightly overpredicts the conversion of the dense phase for higher $X$ (i.e., lower $[C]_{\text {inlet }}$ ) values, whereas it showed a good agreement with conversion data from the complete reactor environment. Also, the $k_{l}$ values shown in Table 2 reveal that the dense phase kinetics overcame $c a$. 1.5-fold the

Table 2. Kinetic parameters obtained from data regression of the experiments in Setup 1 (dense phase) and Setup 2 (complete reactor).

\begin{tabular}{cccc}
\hline Parameter & Unit & Numerical value & CC \\
\hline$k_{1, \text { dense }}$ & $\mathrm{s}^{-1}$ & 0.124 & \\
$k_{1, \text { lean }}$ & $\mathrm{s}^{-1}$ & 0.079 & 0.89 \\
$k_{2}$ & $\mathrm{~m}^{3} \mu \mathrm{mol}^{-1}$ & 0.00104 & \\
\hline
\end{tabular}
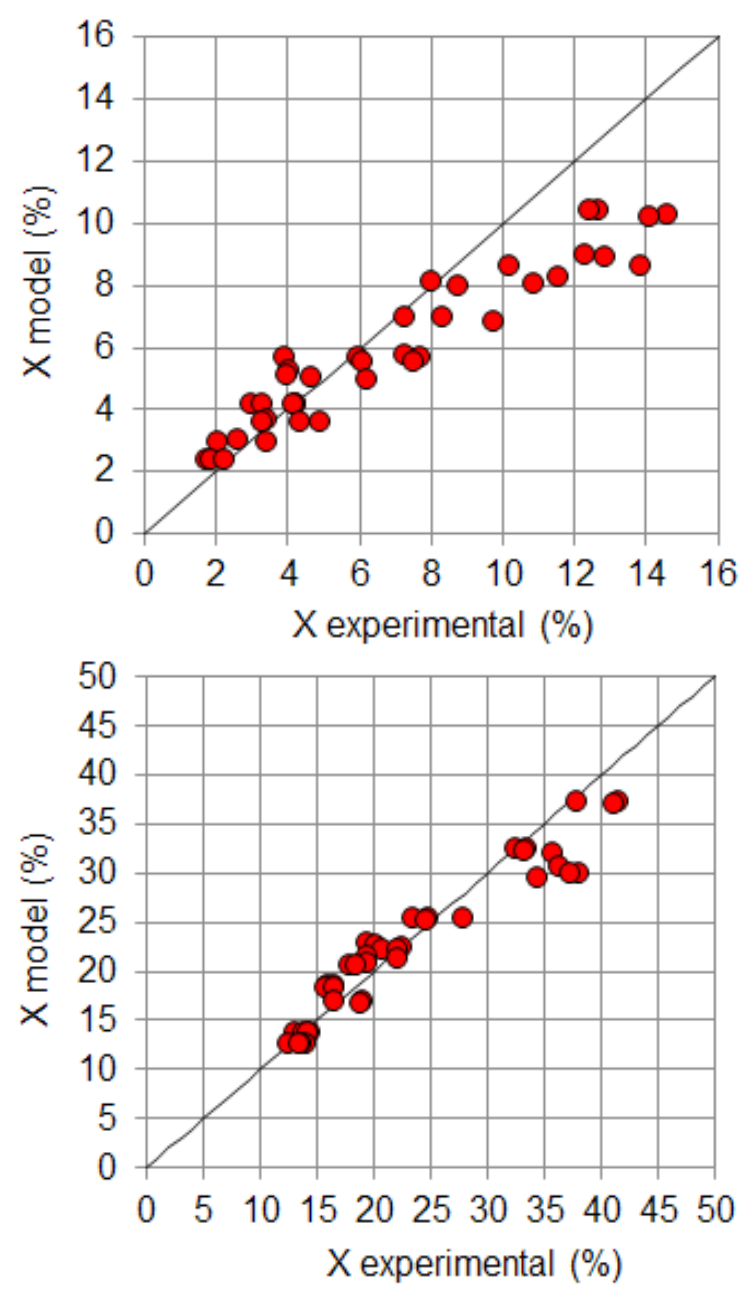

Figure 9. A - Comparison between experimental and model conversions for the dense phase. B - Comparison between experimental and model conversions for the complete reactor.

lean phase kinetics, since these parameters are the ones associated with the reaction specific velocity when $\mathrm{TiO}_{2}$ sites are not saturated. Zhang and Liu (2004) also calculated Langmuir-Hinshelwood parameters for the photocatalytic degradation of hexane, but in an annular photo reactor coated with $\mathrm{TiO}_{2}$. Their values were equivalent to $k_{1}=0.073 \mathrm{~s}^{-1}$ and $k_{2}=0.0044 \mathrm{~m} 3 \mu \mathrm{mol}^{-1}$, showing that the values obtained here are consistent with the literature. Moreover, this comparison suggests that the lean phase of a tall annular fluidized photoreactor, such as the one presented here, is kinetically similar to an annular coated reactor, and that both possess a specific rate lower than a dense phase fluidized reactor on a volumetric basis, which is reasonable since this one contains much more catalyst per unit volume than the other two. Also, the reactor modeled here displayed a considerably lower $k_{2}$ value than that of Zhang and Liu (2004), which would be expected insofar as its dense phase presents a much higher adsorption capacity (more disposable catalyst area) than an annular coated reactor. 


$$
\mathrm{CC}=\frac{\sum\left(\mathrm{X}_{\mathrm{j}}-\overline{\mathrm{X}}\right)\left(\mathrm{Y}_{\mathrm{j}}-\overline{\mathrm{Y}}\right)}{\sqrt{\sum\left(\mathrm{X}_{\mathrm{j}}-\overline{\mathrm{X}}\right)^{2} \sum\left(\mathrm{Y}_{\mathrm{j}}-\overline{\mathrm{Y}}\right)^{2}}}
$$

\section{Model validation}

The proposed model consisted of a CSTR reactor (Equation 2) for the dense phase, since this portion is shorter and bubble formation promotes intense mixing within the bed, and a PFR reactor for the lean phase, given that this part of the reactor resembles a tubular reactor like that modeled by Rochetto and Tomaz (2015). The regions were considered to be two reactors in series, both coupled with LH kinetics parameterized with the values shown in Table 2. In order to assess the proposed model, more steady-state conversions were obtained from assays with Setup 2, initially in the same conditions as those shown in Table 1. Experimental and predicted outlet concentrations are compared in Figure 10. It is important to point out that the ten experimental points presented in this plot did not compose the training set of the model, thus serving as a measurement of the model. It is clear from the high correlation of this pairwise plot $\left(\mathrm{R}^{2}=0.9804\right)$ that the model could successfully predict the reactor performance when operating at $10 \mathrm{~L} \mathrm{~min}^{-1}$ (i.e., $Q=$ $1.67 \times 10^{-4} \mathrm{~m}^{3} \mathrm{~s}^{-1}$ ) and $m=0.1 \mathrm{~kg}$.

In order to verify the extent to which the model is valid, the flow rate was set as $5.0 \mathrm{~L} \mathrm{~min}^{-1}, 7.5 \mathrm{~L}$ $\mathrm{min}^{-1}$ and $15 \mathrm{~L} \mathrm{~min}^{-1}$ (corresponding respectively to $1.0,1.5$ and $3.0 u_{m f}$ ), and $[C]_{\text {inlet }}$ was fixed as ca. $1200 \mu \mathrm{mol} \mathrm{m}{ }^{-3}$. The results are shown in Figure 11. Again, none of the fourteen experiments presented

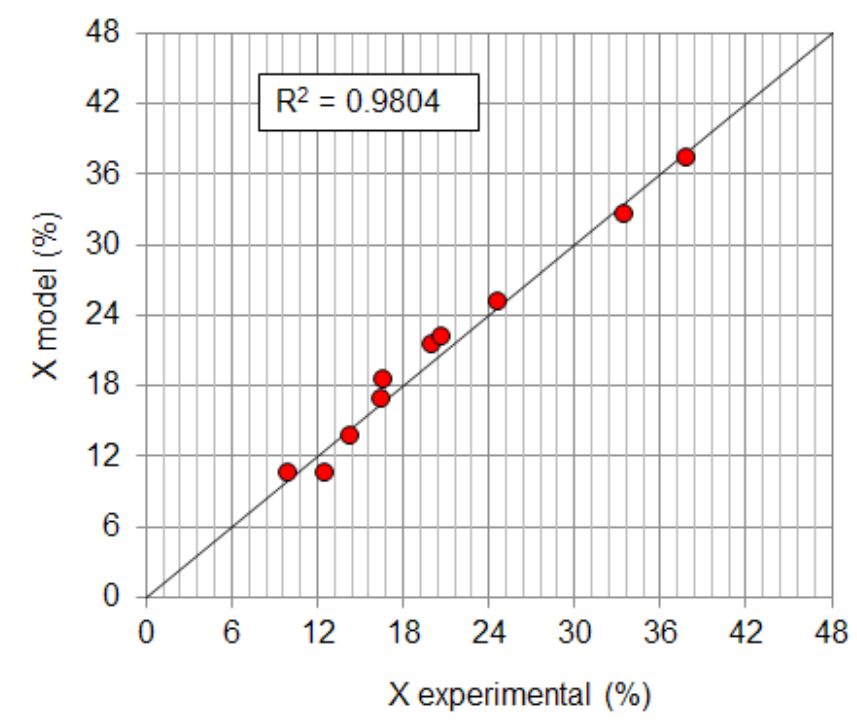

Figure 10. Kinetic model validation (dense phase $=$ CSTR, lean phase $=$ PFR) for experimental conditions set as those in Table 1, that is, $Q=1.67 \times 10^{-4} \mathrm{~m}^{3} \mathrm{~s}^{-1}$ and $m=0.1 \mathrm{~kg}$. in this figure were used in model training. Figure 11 shows a clear trend, in which the model predicts $n$-hexane degradations for the flow rate of $10 \mathrm{~L} \mathrm{~min}^{-}$ 1 , underpredicts degradations for flow rates lower than $10 \mathrm{~L} \mathrm{~min}^{-1}$ and overpredicts degradations for flow rate higher than $15 \mathrm{~L} \mathrm{~min}^{-1}$. Thus, the proposed model was not robust regarding the operation flow rate. In order to discuss this trend, two phenomena must be taken into account. First, when the gas flow rate increases, the dense phase expands and the volume of the lean phase decreases; also, as the dense phase behaves as a bubbling fluidized bed, it is reasonable to assume that the gas passing through the solids is at minimum fluidization velocity, while the excess flow rate bypasses as gas bubbles, which makes the model overpredictive as the flow rate increases. Concomitantly, higher flow rates increase the dense bed voidage and the lean phase solids holdup, enhancing the contact of UV radiation with the fluidized bed particles, and thus making the model underpredictive as the flow rate increases. Given the trend observed in Figure 11, it is clear that the first phenomenon prevails within the reactor. To make a comparison with another model existing in the literature, Dashliborun et al. (2013) represented the dense phase of a similar photoreactor by applying a specific fluidization flow model, and obtained robust results for flow rates varying below $3.0 u_{m p}$; however, for flow rates of $3.0 u_{m f}$ and higher, their model also overpredicted $n$-hexane degradation.

Finally, the model validity was tested for a higher input of photocatalyst mass inside the reactor. In this

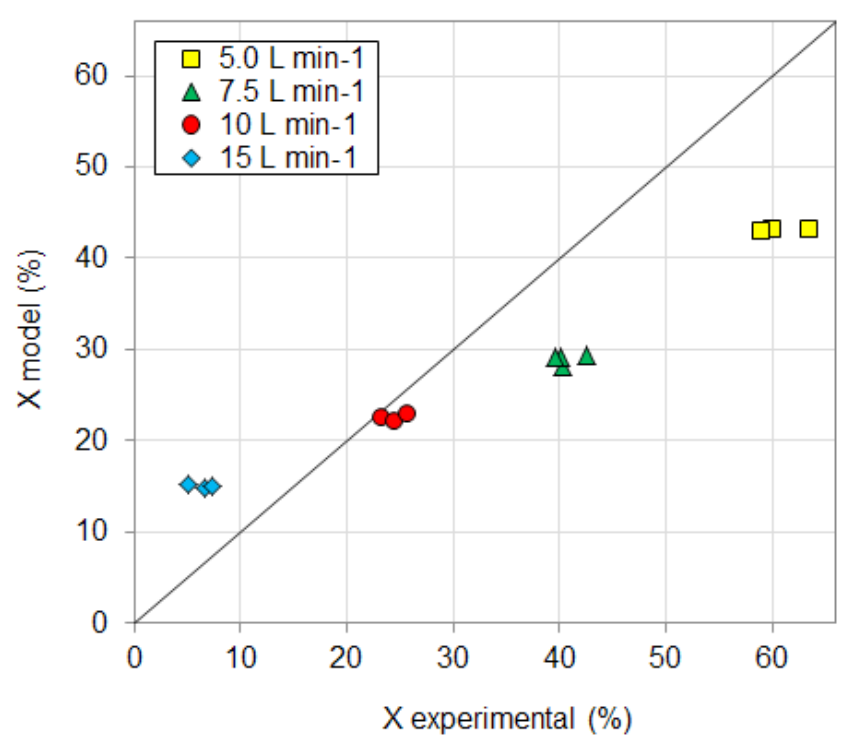

Figure 11. Kinetic model validation (dense phase $=$ CSTR, lean phase $=$ PFR). Flow rates of 5.0, 7.5, 10 and $15 \mathrm{~L} \mathrm{~min}^{-1}$ (i.e. $Q=0.83 \times 10^{-4}, 1.25 \times 10^{-4}, 1.67$ $\times 10^{-4}$ and $\left.2.50 \times 10^{-4} \mathrm{~m}^{3} \mathrm{~s}^{-1}\right), m=0.1 \mathrm{~kg}$ and $[C]_{\text {inlet }}=$ $1200 \mu \mathrm{mol} \mathrm{m}{ }^{-3}$. 
case, $0.2 \mathrm{~kg}$ of $\mathrm{TiO}_{2}$ was used and, as a consequence, $V_{\text {dense }}$ and $V_{\text {lean }}$ parameters had to be revaluated. Flow rate was maintained as $10 \mathrm{~L} \mathrm{~min}^{-1}$ (i.e., $1.67 \times 10^{-4}$ $\mathrm{m}^{3} \mathrm{~s}^{-1}$ ), so the values applied to the model were those shown in Table 3. Figure 12 compares conversion data, revealing a ca. 2-fold increase in conversion as mass was raised from 0.1 to $0.2 \mathrm{~kg}$. In Figure 13, experimental conversion and model conversion are compared. It can be clearly seen that the model grossly underpredicted experimental degradations for a higher mass input. This happens because the CSTR+PFR model is very stiff with regards to the relative volume of its phases.

Table 3. Experimental conditions for the model prediction with higher catalyst load.

\begin{tabular}{lcc}
\hline $\begin{array}{c}\text { Operational } \\
\text { parameter }\end{array}$ & Unit & $\begin{array}{c}\text { Numerical } \\
\text { value }\end{array}$ \\
\hline Mass, $m$ & $\mathrm{~kg}$ & 0.20 \\
Flow rate, $Q$ & $\mathrm{~m}^{3} \cdot \mathrm{s}^{-1}$ & $1.67 \times 10^{-4}$ \\
N-hexane inlet concentration & $\mu \mathrm{mol} \mathrm{m}^{-3}$ & $100-4200$ \\
Photon flow & Einstein s & $0.83 \times 10^{-4}$ \\
Dense phase volume, $V_{\text {dense }}$ & $\mathrm{m}^{3}$ & $3.01 \times 10^{-4}$ \\
Lean phase volume, $V_{\text {lean }}$ & $\mathrm{m}^{3}$ & $7.04 \times 10^{-4}$ \\
\hline
\end{tabular}

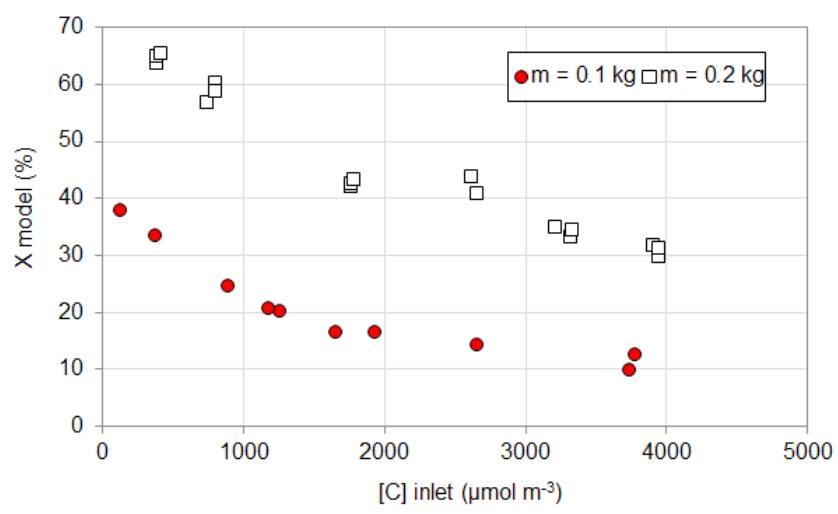

Figure 12. $N$-hexane conversion, comparison between $m=0.1 \mathrm{~kg}$ and $m=0.2 \mathrm{~kg} . Q=1.67 \times 10^{-4} \mathrm{~m}^{3} \mathrm{~s}^{-1}$.

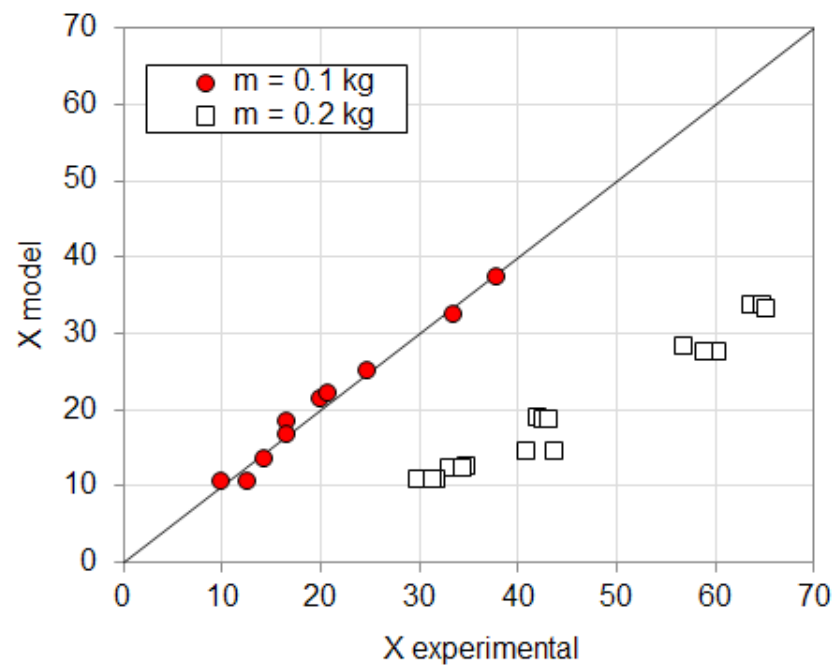

Figure 13. Experimental and calculated conversions for $m=0.1 \mathrm{~kg}$ and $0.2 \mathrm{~kg} . Q=1.67 \times 10^{-4} \mathrm{~m}^{3} \mathrm{~s}^{-1}$.
Therefore, the model cannot represent large variations in bed volumes. Two phenomena can be pointed out as responsible for the much higher conversion when catalyst mass was raised: the increase in volume of the dense phase (which is kinetically faster, as shown in Table 2), and the increase in solids concentration of the lean phase, including particles sticking on the reactor walls. Thus, in order for the model to be valid for $m=$ $0.2 \mathrm{~kg}$, both $k_{1, \text { dense }}$ and $k_{1, \text { lean }}$ values would have to be increased, the first one to outweigh the fact that gas bypass increases as the dense phase volume increases; and the second one to adjust the solids concentration in the lean phase. Even though Dashliborun et al. (2013) verified the effect of other variables such as humidity, they did not assess the deviations caused by catalyst mass in their model. To the best of our knowledge, this is the first work to carry out this comparison in the modeling of a fluidized bed photocatalytic reactor.

\section{CONCLUSIONS}

A kinetic model based on the determination of kinetic parameters in a fluidized bed photoreactor using Langmuir-Hinshelwood kinetics for $n$-hexane degradation was developed. The proposed model divided the photoreactor into two regions: dense phase, treated as a CSTR reactor, and lean phase, represented by a PFR reactor, coupled as two reactors in series. Flow rate $v s$ reaction rate data revealed that the photoreactor was not mass transfer limited in the region of 5.0 - $15.0 \mathrm{~L} \mathrm{~min}^{-1}$. Thus, a Langmuir-type kinetics was assumed and model parameterization was successfully carried out by minimizing the MSE between experimental data and model predictions, which revealed $k_{1, \text { dense }}=0.124 \mathrm{~s}^{-1}, k_{1, \text { lean }}=0.079 \mathrm{~s}^{-1}$ and $k_{2}=0.00104 \mathrm{~m}^{3} \mu \mathrm{mol}^{-1}$, with a correlation coefficient of 0.89 .

The CSTR-PFR model could be successfully validated for the operation conditions for which the model was trained, i.e., $Q=1.67 \times 10^{-4} \mathrm{~m}^{3} \mathrm{~s}^{-1}$ and $m$ $=0.1 \mathrm{~kg}$. However, when operating at different flow rates and catalyst loads inside de reactor, the model lost its predictive capacity. With regards to flow rate, the model underpredicted conversions for flow rates lower than $1.67 \times 10^{-4} \mathrm{~m}^{3} \mathrm{~s}^{-1}$ and overpredicted conversions for flow rates higher than $1.67 \times 10^{-4} \mathrm{~m}^{3} \mathrm{~s}^{-1}$, suggesting that the increase of gas bypassing as bubbles within the fluidized bed could not be predicted by the model. In the case of catalyst load, the model crudely underpredicted conversion data given its stiffness relative to the change of the relative volume between its phases, indicating that, in this case, the kinetic constants should have their values fitted according to diverse phenomena that occurred inside the reactor, such as the increase in the solids concentration of the lean phase. 
Thus, this study shows that the CSTR-PFR model can be used for engineering purposes to describe a fluidized bed photocatalytic reactor. However, the accuracy of the model is sensitive to changes in operational parameters such as flow rate and catalyst load, and more complex models should be developed in order to consider the variations in gas bypass, solids hold-up and UV radiation contact with catalyst particles throughout the reactor.

\section{NOTATION}

\begin{tabular}{|c|c|}
\hline$[C]_{\text {inlet }}$ & $\begin{array}{l}\text { n-hexane concentration in the } \\
\text { photoreactor inlet }\left(\mu \mathrm{mol} \mathrm{m}{ }^{-3}\right)\end{array}$ \\
\hline$[C]_{\text {outlet }}$ & $\begin{array}{l}\text { n-hexane concentration in the } \\
\left.\text { photoreactor inlet }(\mu \mathrm{mol} \mathrm{m})^{-3}\right)\end{array}$ \\
\hline$d$ & Particle diameter $(\mathrm{m})$ \\
\hline $\mathrm{D}_{\mathrm{AB}}$ & Pollutant diffusion coefficient $\left(\mathrm{m}^{2} \mathrm{~s}^{-1}\right)$ \\
\hline$k_{l, \text { dense }}^{\mathrm{AB}}$ & $\begin{array}{l}\text { Reaction rate parameter for the } \\
\text { photocatalytic oxidation of n-hexane } \\
\text { in the dense phase of the photoreactor } \\
\left(\mathrm{s}^{-1}\right)\end{array}$ \\
\hline$k_{1, \text { lean }}$ & $\begin{array}{l}\text { Reaction rate parameter for the } \\
\text { photocatalytic oxidation of } n \text {-hexane } \\
\text { in the dense phase of the photoreactor } \\
\left(\mathrm{s}^{-1}\right)\end{array}$ \\
\hline$k_{2}$ & $\begin{array}{l}\text { Reaction rate parameter for } \mathrm{TiO}_{2} \text { site } \\
\text { saturation in the photocatalytic reactor } \\
\left(\mathrm{m}^{3} \mu \mathrm{mol}^{-1}\right)\end{array}$ \\
\hline$m$ & Catalyst mass (kg) \\
\hline$v$ & Air kinematic viscosity $\left(\mathrm{m}^{2} \mathrm{~s}^{-1}\right)$ \\
\hline MSE & Mean squared error $\left(\mu \mathrm{mol} \mathrm{m} \mathrm{m}^{-3}\right)$ \\
\hline$Q$ & Volumetric flow $\left(\mathrm{m}^{3} \mathrm{~s}^{-1}\right)$ \\
\hline$r_{A}$ & $n$-hexane degradation rate $\left(\mu \mathrm{mol} \mathrm{s}^{-1}\right)$ \\
\hline$R_{\text {phase }}$ & $\begin{array}{l}n \text {-hexane reaction rate in specific } \\
\text { phase }\left(\mu \mathrm{mol} \mathrm{m} \mathrm{m}^{-3} \mathrm{~s}^{-1}\right)\end{array}$ \\
\hline$U$ & $\begin{array}{l}\text { Gas velocity over a single particle } \\
\left(\mathrm{m} \mathrm{s}^{-1}\right)\end{array}$ \\
\hline$u$ & Gas superficial velocity $\left(\mathrm{m} \mathrm{s}^{-1}\right)$ \\
\hline & Minimum fluidization velocity $\left(\mathrm{m} \mathrm{s}^{-1}\right)$ \\
\hline & Dense phase irradiated volume $\left(\mathrm{m}^{3}\right)$ \\
\hline$V^{\text {lean }}$ & Lean phase irradiated volume $\left(\mathrm{m}^{3}\right)$ \\
\hline
\end{tabular}

\section{ACKNOWLEDGEMENTS}

The authors express their gratitude to the Coordination for the Improvement of Higher Level Personnel (CAPES, Brazil, finance code 001), the National Council for Scientific and Technological Development ( $\mathrm{CNPq}$, Brazil), and the São Paulo Research Foundation (FAPESP, grant PIPE $\mathrm{n}^{\circ}$ 2016/00953-6) for the financial support. We also thank $\mathrm{Ph}$. D. Marilda Viana for her aid with chromatographic analysis.

\section{REFERENCES}

Alberici, R. M., Jardim, W. F. Photocatalytic destruction of VOCs in the gas-phase using titanium dioxide. Applied Catalysis B: Environmental, 14, 55-68 (1997). https://doi.org/10.1016/S09263373(97)00012-X

Assadi, A. A., Bouzaza, A., Merabet S., Wolbert D. Modeling and simulation of VOCs removal by nonthermal plasma discharge with photocatalysis in a continuous reactor: Synergetic effect and mass transfer. Chemical Engineering Journal, 258, 119-127 (2014). https://doi.org/10.1016/j. cej.2014.07.050

Assadi, A. A., Bouzaza, A., Merabet, S., Wolbert D. Study of synergetic effect by surface discharge plasma/ $\mathrm{TiO}_{2}$ combination for indoor air treatment: Sequential and continuous configurations at pilot scale. Journal of Photochemistry and Photobiology A: Chemistry, 310, 148-154. (2015). https://doi. org/10.1016/j.jphotochem.2015.05.007

Boyjoo, Y., Sun, H., Liu, J., Pareek, V. K., Wang, S. A review on photocatalysis for air treatment: from catalyst development to reactor design. Chemical Engineering Journal, 310, 537-559 (2017). https:// doi.org/10.1016/j.cej.2016.06.090

Dashliborun, A. M., Sotudeh-Gharebagh, R., Hajaghazadeh, M., Kakooei, H., Afshar, S. Modeling of the photocatalytic degradation of methyl ethyl ketone in a fluidized bed reactor of nano- $\mathrm{TiO}_{2} / \gamma-\mathrm{Al}_{2} \mathrm{O}_{3}$ particles. Chemical Engineering Journal, 226, 59-67 (2013). https:// doi.org/10.1016/j.cej.2013.04.022

Diniz, L. A., Hewer, T. L. R., Matsumoto, D., Teixeira, A.C. S. C. A Comparison Between the Four Geldart Groups on the Performance of a Gas-phase Annular Fluidized Bed Photoreactor for Volatile Organic Compound Oxidation. Environmental Science and Pollution Research, 26, 4242-4252 (2019). https:// doi.org/10.1007/s11356-018-2145-5

Geng, Q., Guo, Q., Cao, C., Wang, L. Investigation into Photocatalytic Degradation of Gaseous Ammonia in CPCR. Industrial \& Engineering Chemistry Research, 47, 2561-2568 (2008). https:// doi.org/10.1021/ie071507m

Geng, Q., Guo, Q., Cao, C., Wang, L. Investigation into $\mathrm{NanoTiO}_{2} / \mathrm{ACSPCR}$ for Decomposition of Aqueous Hydroquinone. Industrial \& Engineering Chemistry Research, 47, 4364-4368 (2008). https:// doi.org/10.1021/ie071507m

Hashimoto, K., Irie, H., Fujishima, A. $\mathrm{TiO}_{2}$ Photocatalysis : A Historical Overview and Future Prospects. Japanese Journal of Applied Physics, 44, 8269-8285 (2006). https://doi.org/10.1143/ JJAP.44.8269 
Imoberdorf, G. E., Cassano, A. E., Irazoqui, H. A., Alfano, O. M. Simulation of a multi-annular photocatalytic reactor for degradation of perchloroethylene in air: Parametric analysis of radiative energy efficiencies. Chemical Engineering Science, 62, 1138-1154 (2007). https://doi. org/10.1016/j.ces.2006.10.024

Kim, S. B., Hong, S. C. Kinetic study for photocatalytic degradation of volatile organic compounds in air using thin film $\mathrm{TiO}_{2}$ photocatalyst. Applied Catalysis B: Environmental, 35, 305-315 (2002). https://doi.org/10.1016/S0926-3373(01)00274-0

Kunii, D., Levenspiel O. Fluidization engineering. Butterworth- Heinemann, Boston (1991).

Kuo, H. P., Wu, C. T., Hsu, R. C. Continuous toluene vapour photocatalytic deduction in a multi-stage fluidised bed. Powder Technology, 210, 760-762 (2011). https://doi.org/10.1016/j. powtec.2011.03.022

Lim, T. H., Kim, S. D. Photo-degradation characteristics of TCE (trichloroethylene) in an annulus fluidized bed photoreactor. Korean Journal of Chemical Engineering, 21, 905-909 (2004). https://doi. org/10.1007/BF02705538

Park, J.-H., Seo, Y. S., Kim, H. S., Kim, I. $\mathrm{K}$. Photodegradation of benzene, toluene, ethylbenzene and xylene by fluidized bed gaseous reactor with $\mathrm{TiO}_{2} / \mathrm{SiO}_{2}$ photocatalysts. Korean Journal of Chemical Engineering, 28, 1693-1697 (2011). https://doi.org/10.1007/s11814-011-0021-9

Prieto, O., Fermoso, J., Irusta, R. Photocatalytic Degradation of Toluene in Air Using a Fluidized Bed Photoreactor. International Journal of Photoenergy, 2007, 1-9 (2007). https://doi. org/10.1155/2007/32859

Rochetto, U. L., Tomaz, E. Degradation of volatile organic compounds in the gas phase by heterogeneous photocatalysis with titanium dioxide/ultraviolet light. Journal of the Air \& Waste Management Association, 65, 810-817 (2015). https://doi.org/10.1080/10962247.2015.1020117

Sleiman, M., Conchon, P., Ferronato, C., Chovelon, J. Photocatalyticoxidation oftolueneatindoorairlevels (ppbv): Towards a better assessment of conversion, reaction intermediates and mineralization. Applied Catalysis B: Environmental, 86, 159-16 (2009). https://doi.org/10.1016/j.apcatb.2008.08.003

Tang, W. Z. Physicochemical Treatment of Hazardous Wastes. CRC Press, Boca Raton, Florida (2000)

United States Environmental Protection Agency. Toxicological Review of $n$-HEXANE. U.S. Environmental Protection Agency, Washington, p. 223 (2005).

Yao, S. W., Kuo, H. P. Photocatalytic Degradation of Toluene on $\mathrm{SiO}_{2} / \mathrm{TiO}_{2}$ Photocatalyst in a Fluidized Bed Reactor. Procedia Engineering, 102, 1254-1260 (2015). https://doi.org/10.1016/j. proeng.2015.01.254

Yue, P. L., Khan, F., Rizzuti, L. Photocatalytic ammonia synthesis in a fluidised bed reactor. Chemical Engineering Science, 38, 1893-1900 (1983). https://doi.org/10.1016/0009-2509(83)85045-3

Zhang P., Liu, J. Photocatalytic degradation of trace hexane in the gas phase with and without ozone addition: kinetic study. Journal of Photochemistry Photobiology A: Chemistry, 167, 87-94 (2004). https://doi.org/10.1016/j.jphotochem.2004.05.015

Zhong, J., Wang, J., Tao, L., Gong, M., Zhimin, L., Chen, Y. Photocatalytic degradation of gaseous benzene over $\mathrm{TiO}_{2} / \mathrm{Sr}_{2} \mathrm{CeO}_{4}$ : kinetic model and degra degradation mechanisms. Journal of Hazardous Materials, 139, 323-31 (2007). https:// doi.org/10.1016/j.jhazmat.2006.06.036 